\title{
Easy modification of the endograsp instrument
}

The Endograsp (USSC) instrument (Fig. 1), an adjustable, near- $-90^{\circ}$ clamp, has greatly facilitated laparoscopic procedures. It is particularly useful for passing Penrose drains and the gastric fundus through the retroesophageal space during fundoplications. The large $80^{\circ}$ distal curve attainable with this instrument allows for near-right-angle manipulation intraabdominally while still using a rigid $5-\mathrm{mm}$ cylindrical

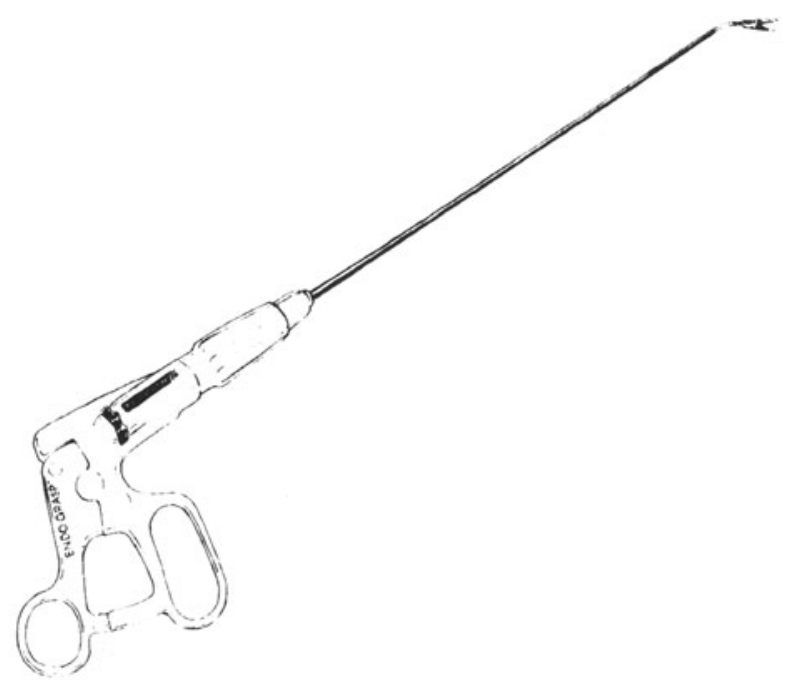

Fig. 1. Endograsp instrument.

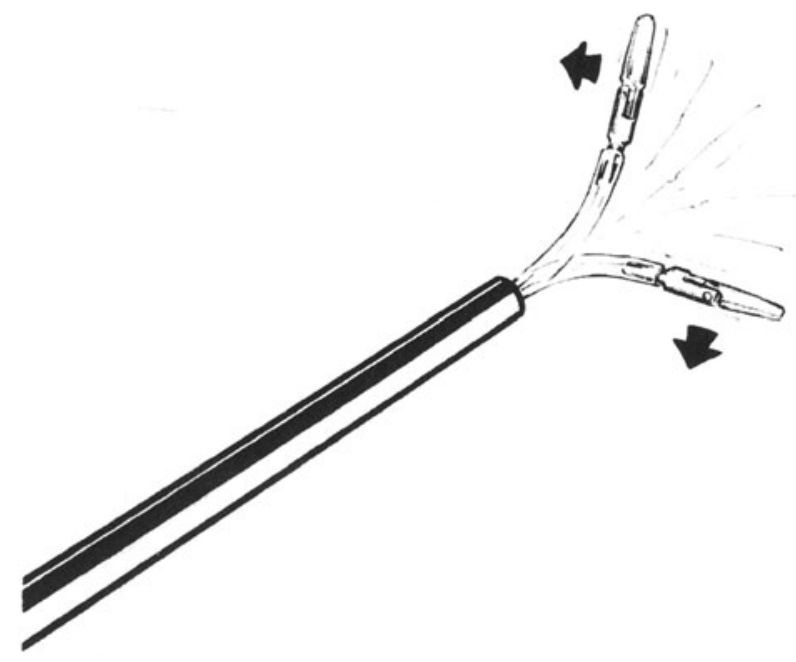

Fig. 2. Axial rotation.

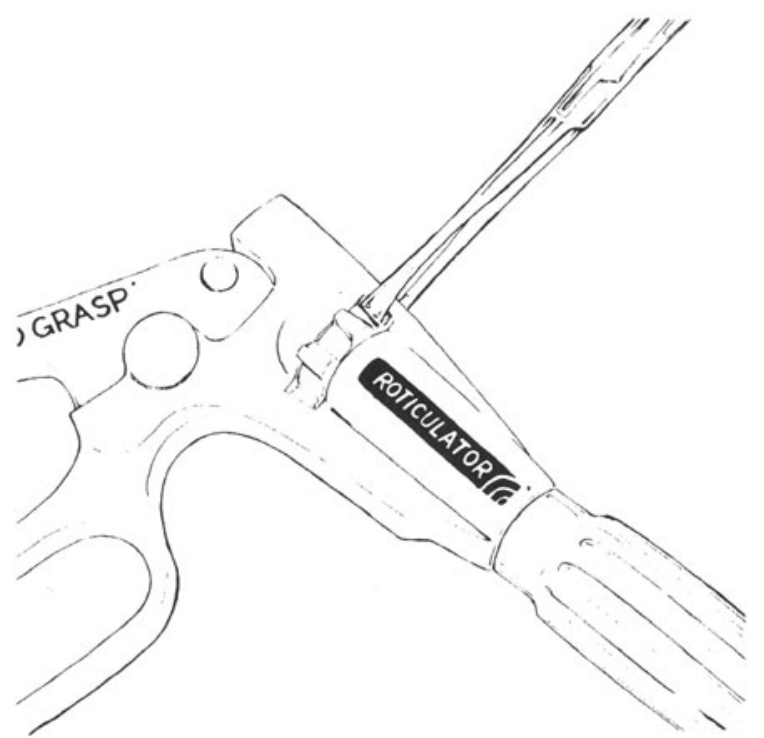

Fig. 3. Allis clamp modification.

port. Unfortunately, we have encountered relatively uncontrolled axial rotation of the deployed distal tip (Fig. 2). This occurred when a rotational load was placed on the deployed segment of the clamp. The finger wheel designed to counteract this can be difficult to adequately control. The potential danger of a clamp rotating in the retroesophageal space is easy to understand.

We have adopted a simple solution to this problem. An Allis clamp is applied to the finger wheel once the distal tip is deployed in the desired plane intraabdominally (Fig. 3). This has solved the problem of unwanted rotation rapidly, reliably, and inexpensively.

To date we have experienced no complications from using this instrument, and with this modification, we expect to have none in the future.

\section{J. R. Gusz \\ S. R. Vallance \\ M. Harkabus}

General Surgery Service

Ireland Army Community Hospital

Fort Knox, KY 40121-5520 USA

The opinions expressed in this article are those of the authors and do not reflect the official policy or position of the Department of the Army, Department of Defense, or the United States Government 